\title{
O Uso de Imagens em Redes Sociais e o Respeito ao Paciente Odontológico
}

\section{The Use of Images in Social Networks and the Respect for the Dental Patient}

\author{
Leandro Brambilla Martorella*; Wanderson Flor do Nascimento ${ }^{\mathrm{a}}$; Mauro Machado do Prado ${ }^{\mathrm{b}}$; Rhonan Ferreira Silva ${ }^{\mathrm{b}}$; \\ Solon Diego Santos Carvalho Mendes
}

${ }^{a}$ Universidade de Brasília, Programa de Pós-Graduação em Bioética, DF, Brasil

bUniversidade Federal de Goiás, GO, Brasil

*E-mail: 1bmartorel1@gmail.com

Recebido: 11 de abril de 2015; Aceito: 19 de julho de 2015

\begin{abstract}
Resumo
A relação profissional de saúde-paciente requer uma série de condições para que o serviço de cuidado possa ser prestado com segurança, beneficiando ao máximo os sujeitos envolvidos. Uma destas condições está relacionada a alguns deveres dos profissionais de saúde para com os pacientes: respeito à autonomia, à privacidade e à confidencialidade das informações obtidas. Esses deveres podem estar comprometidos quando os profissionais de saúde desenvolvem como prática a publicação de imagens de pacientes em redes sociais. O objetivo deste trabalho foi analisar sob uma perspectiva ética e legal as imagens da rede social virtual conhecida por Instagram em que apareçam pacientes odontológicos utilizando palavras-chave que recuperassem imagens associadas às diversas especialidades odontológicas. Por meio de análise de conteúdo, identificou-se que cirurgiões-dentistas têm publicado imagens de pacientes que neste trabalho foram classificadas em cinco categorias: procedimento; antes e depois; caso clínico; pose com paciente; exames complementares e afins. Foram avaliadas 123 imagens sendo os maiores responsáveis pelas publicações perfis de cirurgiões-dentistas (46,4\%) e de estudantes de odontologia (28,5\%). A publicação de imagem de pacientes em redes sociais é contraindicada por argumentos fundamentados em perspectivas ética e legal, podendo até mesmo trazer aos profissionais de saúde problemas de ordens administrativa, cível e penal.
\end{abstract}

Palavras-chave: Rede Social. Ética Odontológica. Confidencialidade.

Abstract

The health professional-patient relationship requires a series of conditions for which the care service can be provided with safety, benefiting at the most the subjects involved. One of these conditions is related to some duties of health professionals with the patients: respect to autonomy, to privacy and the confidentiality of the information obtained. These duties can be compromised when health professionals develop as practice the publication of patient images in social networks. The objective of this work was to analyze under a legal and ethical perspective the images of the social network virtual known by Instagram where odontological patients appear using keywords that recover images associated to the various specialized dental services. By means of the content analysis, it was identified that dental surgeons have published images of patients which in this study were classified into five categories: procedure; before and after; clinical case; posturing with patient; complementary exams and suchlike. 123 images were evaluated being the most responsible for publications profiles of dental surgeons (46.4\%) and of dental students $(28.5 \%)$. The publication of patients images in social networks is contraindicated by arguments substantiated in legal and ethical perspective, and may even bring to health professionals problems of administrative orders, civil and criminal matters.

Keywords: Social Networking. Ethics, Dental. Confidentiality.

\section{Introdução}

Em geral, para o estabelecimento de uma relação de cuidado em saúde, é necessário que o profissional do setor tenha acesso a informações privadas e íntimas das pessoas, informações que podem tanto ser verbalizadas pelos pacientes, como no caso daquelas informadas pela anamnese, quanto observadas, pela permissão do acesso direto ao corpo físico, quando da execução dos exames clínico, laboratorial ou por imagens ${ }^{1}$.

Um dos tipos de informação de pacientes que é registrada por imagem é a fotografia de partes ou totalidade do corpo, a depender da área específica de atuação profissional. Podese afirmar que os profissionais de saúde, especialmente os cirurgiões-dentistas - CD, que utilizam essa ferramenta, o fazem para documentar o caso clínico, sendo etapa importante para o planejamento do caso, acompanhamento e observação dos resultados, assim, as fotografias são parte integrante do prontuário clínico. Um segundo motivo para esse registro fotográfico seria o interesse de divulgação do caso clínico em meio científico e acadêmico e, terceiro, seria um meio de divulgação dos serviços prestados pelo profissional de saúde ${ }^{2}$. Os dois últimos motivos requerem especial cautela, pois, a depender dos seus métodos de execução e veiculação, podem gerar questionamentos em âmbito ético-administrativo, cível e penal, uma vez que estão garantidos ao paciente os direitos à privacidade e confidencialidade de suas informações.

Nesse contexto, é imprescindível que o profissional de saúde informe o paciente em relação ao momento em que irá realizar o registro da imagem, além de especificar as finalidades, condições e circunstâncias em que suas informações serão utilizadas e/ou 
veiculadas. O processo de obtenção do consentimento livre e esclarecido traduz o cuidado do profissional de saúde com seu paciente, bem como seu respeito aos princípios da dignidade humana e da decisão autônoma ${ }^{3}$.

Por outro lado, com a popularização das redes sociais virtuais tem-se notado que cada vez mais na sociedade da informação, existe tendência a maior dificuldade em controlar e identificar o que é público e privado ${ }^{4}$. Sendo possível encontrar diversos exemplos nos quais as pessoas são prejudicadas por divulgarem espontaneamente informações privadas de suas vidas nas redes sociais ${ }^{5}$.

Entretanto, a situação se torna mais complexa quando as informações de alguns indivíduos são divulgadas publicamente nas redes sociais, não pela vontade deles mesmos, mas pela ação de terceiros. Mais preocupante ainda se essas informações são reveladas por profissionais de saúde, que por meio de suas atividades profissionais tiveram acesso direto e íntimo aos pacientes. Desse modo, o CD que utiliza as ferramentas das redes sociais virtuais deve ter em mente que sua prática profissional é privada, bem como as informações que obtém de seus pacientes ${ }^{6}$.

A sociedade brasileira tem se demonstrado mais atenta aos seus direitos civis e de consumidor, especialmente avaliandose o aumento no número de processos sofridos por $\mathrm{CD}$ em algumas regiões do País, com a importante ressalva de decisões já terem sido proferidas em desfavor dos profissionais e com indenizações por danos morais e materiais, alcançando valores que ultrapassam trezentos mil reais ${ }^{7}$.

O CD que respeita a dignidade de seus pacientes e as normas éticas e legais do País consegue também ao mesmo tempo se proteger de ações ético-administrativas, cíveis e penais $^{8}$. Em um contexto onde as tecnologias têm ganhado espaço de maneira muito rápida, é importante que se discutam os impactos do uso das mídias sociais na vida dos profissionais da odontologia. Assim, o objetivo deste trabalho foi analisar, sob uma perspectiva ética e legal, as imagens de pacientes odontológicos que aparecem em uma rede social conhecida como Instagram.

\section{Material e Métodos}

Este trabalho não foi submetido a um Comitê de Ética em Pesquisa (CEP) para avaliação segundo as normas da Resolução do Conselho Nacional de Saúde de número $466 / 2012$, porque se trata de um estudo que coletou informações publicadas em rede social de abrangência mundial e com perfis públicos. Em analogia, poder-se-ia comparar este estudo com outros que buscam empiricamente analisar publicidades ou outras peças que estão publicadas e são acessíveis ao público em geral.

Assim, trata-se de um estudo empírico que inicialmente utiliza como instrumento para coleta de dados a consulta a uma rede social virtual para a análise documental de fotografias e, posteriormente, como instrumento avaliativo, a análise de conteúdo, incluindo suas etapas de leitura flutuante, seleção das unidades de análise e processo de categorização ${ }^{11}$.

Interessa a este trabalho, especificamente, a rede social conhecida como Instagram, pois permite ao usuário que possui um aparelho com câmera e acesso à internet a publicação instantânea de fotos na $W e b$, seja exclusivamente na própria rede, quanto concomitantemente em outras redes sociais de grande impacto como o Facebook, Twitter, Tumblr ou Flickr. Assim, o Instagram permite uma veiculação de imagens em larga escala.

Para ter um perfil no Instagram, o usuário deve cadastrarse previamente e criar seu nome de login e senha para poder gerenciar sua conta, optando por uma modalidade de divulgação pública, em que todos podem ver seus registros, ou uma privada, na qual determina, mediante as solicitações de outros usuários, aqueles que podem ou não ter acesso às imagens que publica, ou seja, que podem seguir as suas publicações.

O usuário conta ainda com a possibilidade de marcar suas fotos com palavras-chave, conhecidas entre os internautas por hashtags, simbolizadas pelo sustenido (\#), seguido pela palavra ou expressão que gostaria de associar à imagem. Por exemplo, em uma fotografia de uma criança escovando os dentes, o usuário pode marcar a imagem com "\#semcárie" ou "\#escovemOsDentes". Essa marcação tem uma utilidade: quando outros usuários têm interesse em algum item ou temática, podem buscar essas palavras-chave e encontrar imagens de usuários com gostos em comum.

Neste trabalho foram pesquisadas palavras-chave (hashtags) relacionadas à Odontologia na ferramenta de busca da rede social Instagram, tomando-se como referência o nome das 19 especialidades odontológicas reconhecidas pelo Conselho Federal de Odontologia $(\mathrm{CFO})^{10}$. Entretanto, excluíram-se aquelas especialidades que não apresentam como atividade central o atendimento terapêutico direto ao paciente em clínica odontológica ou ambiente hospitalar. Assim, foram excluídas as especialidades de Odontologia Legal, Odontologia do Trabalho e Saúde Coletiva e da Família. Fizeram, então, parte das buscas 32 palavras relacionadas a 16 especialidades odontológicas. $\mathrm{O}$ nome dessas especialidades bem como das palavras-chave utilizadas na busca estão relatadas no Quadro 1.

Quadro 1: Palavras-chave e quantidade de imagens selecionadas para análise por especialidade

\begin{tabular}{|l|c|c|}
\hline \multicolumn{1}{|c|}{ Especialidade } & $\begin{array}{c}\text { Palavras-chave } \\
\text { associadas (\#) }\end{array}$ & $\begin{array}{c}\text { Continua ... } \\
\text { Fotos } \\
\text { selecionadas }\end{array}$ \\
\hline \multirow{3}{*}{$\begin{array}{l}\text { Cirurgia e } \\
\text { Traumatologia Buco- } \\
\text { Maxilo-Faciais }\end{array}$} & bucomaxilo & 4 \\
\cline { 2 - 3 } & bucomaxilofacial & 3 \\
\cline { 2 - 3 } & ortognática & 2 \\
\cline { 2 - 3 } & ortognática & 1 \\
\hline \multirow{4}{*}{ Dentística } & dentística & 6 \\
\cline { 2 - 3 } & dentística & 2 \\
\cline { 2 - 3 } & Odontologia estética & 2 \\
\hline
\end{tabular}




\begin{tabular}{|c|c|c|}
\hline Especialidade & $\begin{array}{l}\text { Palavras-chave } \\
\text { associadas (\#) }\end{array}$ & $\begin{array}{c}\text {... Continuação } \\
\text { Fotos } \\
\text { selecionadas }\end{array}$ \\
\hline \multirow{2}{*}{$\begin{array}{l}\text { Disfunção Têmporo- } \\
\text { Mandibular e Dor } \\
\text { Oro-Facial }\end{array}$} & dor orofacial & 3 \\
\hline & temporomandibular & 2 \\
\hline \multirow{2}{*}{ Endodontia } & endodontia & 8 \\
\hline & Tratamento de canal & 2 \\
\hline \multirow{2}{*}{ Estomatologia } & estomatologia & 3 \\
\hline & estomato & 6 \\
\hline \multirow{2}{*}{$\begin{array}{l}\text { Radiologia } \\
\text { Odontológica e } \\
\text { Imaginologia }\end{array}$} & Radiologia odontológica & 1 \\
\hline & radiologiabucal & 1 \\
\hline \multirow{3}{*}{ Implantodontia } & implantodontia & 16 \\
\hline & implantedental & 1 \\
\hline & Implante dentário & 5 \\
\hline Odontogeriatria & odontogeriatria & 3 \\
\hline $\begin{array}{l}\text { Odontologia para } \\
\text { Pacientes com } \\
\text { Necessidades Especiais }\end{array}$ & pacientes especiais & 6 \\
\hline Odontopediatria & odontopediatria & 9 \\
\hline \multirow{2}{*}{ Ortodontia } & ortodontia & 13 \\
\hline & Aparelho ortodôntico & 5 \\
\hline \multirow{2}{*}{$\begin{array}{l}\text { Ortopedia Funcional } \\
\text { dos Maxilares }\end{array}$} & ortopedia funcional & 1 \\
\hline & $\begin{array}{c}\text { ortopedia funcional dos } \\
\text { maxilares }\end{array}$ & 2 \\
\hline Patologia Bucal & patologiabucal & 1 \\
\hline Periodontia & periodontia & 10 \\
\hline \multirow{3}{*}{ Prótese Dentária } & prótese dentária & 2 \\
\hline & prótese fixa & 3 \\
\hline & prótese removível & 0 \\
\hline \multicolumn{2}{|c|}{ Total } & 123 \\
\hline
\end{tabular}

Fonte: Dados da pesquisa.

Para cada palavra-chave pesquisada encontrava-se um número que representa a quantidade de imagens que foram marcadas por esses hashtags até o dia da busca. Ressalta-se que os pesquisadores só tinham acesso às imagens publicadas por perfis públicos, o que impossibilitou a verificação de todas as imagens marcadas, não guardando a este trabalho, portanto, nenhuma pretensão quantitativa. Em seguida, realizou-se uma observação geral das imagens acessadas e, a partir daí, selecionou-se as imagens que permitiam a identificação de casos clínicos ou pacientes. Assim, tratou-se de uma seleção intencional da amostra possibilitando a coleta de dados que apresentam maior potencial em contribuir para que o pesquisador possa entender o problema e a questão da pesquisa9.

Após a seleção intencional das imagens, deu-se início à etapa de leitura flutuante destas. Sequencialmente, as unidades de análise foram selecionadas, avaliava-se nas imagens o enquadramento, foco e recorte, as pessoas que apareciam, como e se elas posavam para a tomada fotográfica. Nessa etapa também se buscou conhecer o perfil do usuário que havia publicado a imagem - profissional, estudante, clínica, blog ou paciente. Por fim, com o processo de categorização, foram utilizadas cinco categorias de classificação de imagens: procedimento; antes e depois; caso clínico; pose com paciente; exames complementares e afins. A coleta de dados foi feita no dia 11 de dezembro de 2013. São critérios de inclusão perfis públicos de usuários e presença de paciente em fotografias. Foram excluídos os perfis que não permitiam acesso à fotografia, os perfis de estrangeiros e imagens sem a presença de paciente.

Ressalta-se novamente que por se tratar de imagens veiculadas em ambiente público, ou seja, de acesso a qualquer usuário da internet com acesso à referida rede social, não se identificou a necessidade de submissão da pesquisa ao comitê de ética em pesquisa.

\section{Resultados e Discussão}

Estiveram associadas às 32 palavras-chave 36.219 imagens, sendo selecionadas para análise um total de 123 (Quadro 1). Ressalta-se que grande parte das imagens não puderam ser acessadas porque se tratavam de perfis privados, ou seja, não permitiam o acesso dos pesquisadores. Do restante das imagens, isto é, das imagens públicas que eram acessíveis aos pesquisadores, aplicavam-se os critérios de inclusão e de exclusão, neste caso, a presença da figura do paciente. Assim, justificam-se os números alcançados e expressos no Quadro 1. A média de imagens avaliadas por especialidade foi de 7,7, e a especialidade com mais imagens avaliadas foi a de Implantodontia (22) e, para a especialidade de Prótese Bucomaxilofacial, não foi encontrado nenhum registro com exposição de paciente.

Quanto ao responsável pelas publicações (Quadro 2), constatou-se que a maioria das imagens estava associada ao perfil de um cirurgião-dentista $(46,4 \%)$, seguido pelo perfil de estudantes de odontologia $(28,5 \%)$, clínica ou consultório odontológico $(9,7 \%)$, paciente $(6,5 \%)$ e publicações de blogs $(5,7 \%)$.

Quadro 2: Quantidade de imagens avaliadas por perfil de usuário

\begin{tabular}{|l|c|c|}
\hline Perfil & $\begin{array}{c}\text { Quantidade de } \\
\text { imagens avaliadas }\end{array}$ & Percentual \\
\hline CD & 57 & $46,4 \%$ \\
\hline Estudantes & 35 & $28,5 \%$ \\
\hline Clínica/ Consultório & 12 & $9,7 \%$ \\
\hline Paciente & 8 & $6,5 \%$ \\
\hline Blog & 7 & $5,7 \%$ \\
\hline Fisioterapeuta & 4 & $3,2 \%$ \\
\hline Total & $\mathbf{1 2 3}$ & $\mathbf{1 0 0 \%}$ \\
\hline
\end{tabular}

Fonte: Dados da pesquisa.

Quanto ao tipo de exposição revelada nas imagens (Quadro $3)$, notou-se que a maioria $(44,8 \%)$ estava relacionada ao transoperatório, ou seja, revelava etapas procedimentais para 
a execução de casos clínicos. Seguiram com maior frequência as exposições do tipo "antes e depois" $(21,1 \%)$, em que eram apresentadas imagens do paciente antes da intervenção clínica e depois da execução dos serviços odontológicos; e de "caso clínico" (13\%), no qual ou eram apresentadas imagens de casos clínicos sem diagnóstico, em que o usuário dava informações complementares do paciente e solicitava auxílio de colegas para a discussão de caso, servindo assim como um fórum de discussão de caso clínico, ou imagens que apresentavam somente um resultado final de intervenção odontológica.

Quadro 3: Tipo de exposição de paciente nas imagens

\begin{tabular}{|l|c|c|}
\hline \multicolumn{1}{|c|}{ Tipo de Exposição } & $\begin{array}{c}\text { Quantidade } \\
\text { de imagens }\end{array}$ & Percentual \\
\hline Procedimento & 55 & $44,8 \%$ \\
\hline Antes e depois & 26 & $21,1 \%$ \\
\hline Caso clínico & 16 & $13 \%$ \\
\hline Pose com paciente & 15 & $12,2 \%$ \\
\hline Sorriso & 3 & $2,4 \%$ \\
\hline Exames complementares e outros & 8 & $6,5 \%$ \\
\hline Total & $\mathbf{1 2 3}$ & $\mathbf{1 0 0 \%}$ \\
\hline
\end{tabular}

Fonte: Dados da pesquisa.

Ao se avaliar apenas aquelas publicações em que há, ou deveria haver, um cirurgião-dentista como responsável, encontrou-se um total de 76 imagens $(61,7 \%)$, ou seja, tratase de publicações em perfis em que os Conselhos Regionais de Odontologia (CROs) podem e devem fiscalizar, cabendo inclusive a abertura de processo ético ex-officio por infringir o código de ética odontológica (CEO) nos artigos Art. 14 (incisos I e III) e Art. 44 (inciso XII). A distribuição do tipo de exposição das imagens segue percentual conforme mostra o Quadro 4.

Quadro 4: Exposição com repercussão ética-administrativa em desfavor de CD (CD, Clínicas e Blogs)

\begin{tabular}{|c|c|c|}
\hline $\begin{array}{c}\text { Tipo de exposição com repercussão } \\
\text { ética em desfavor de CD }\end{array}$ & Quantidade & Percentual \\
\hline Procedimento & 32 & $42,2 \%$ \\
\hline Antes e depois & 20 & $26,4 \%$ \\
\hline Caso clínico & 16 & $21 \%$ \\
\hline Pose com paciente & 3 & $3,9 \%$ \\
\hline Sorriso & 0 & 0 \\
\hline Exames complementares e outros & 5 & $6,5 \%$ \\
\hline Total & $\mathbf{7 6}$ & $\mathbf{1 0 0} \%$ \\
\hline
\end{tabular}

Fonte: Dados da pesquisa.

Neste trabalho evidenciou-se que $28,5 \%$ das imagens publicadas estavam relacionadas a perfis de estudantes de odontologia. Ainda que esse grupo não esteja regulamentado pelas normas do CFO, frequentemente suas publicações estão associadas a uma instituição de ensino que tem normativa específica e que pela ação do aluno pode ter sua imagem exposta e prejudicada. É interessante que exista na formação em odontologia atividades que estimulem o desenvolvimento moral dos acadêmicos sob o risco de existir consequências danosas para o futuro profissional, pacientes e a sociedade ${ }^{12}$.

Também é interessante destacar que pacientes $(6,5 \%)$ divulgaram imagem de seus corpos, evidenciando os resultados obtidos após tratamentos odontológicos ou exibindo imagens de pós-operatório. Alguns autores acreditam que esse processo de a autorrevelação pode acontecer mais rapidamente quando são utilizados os meios virtuais de comunicação, ${ }^{16}$ apontando para a necessidade de maior cautela por parte dos usuários e também dos pais que permitem aos seus filhos menores de idade a criação desses perfis. Embora esses casos não sejam moralmente problemáticos, no que tange à privacidade e à autonomia, visto que as pessoas proprietárias das informações são as veiculadoras, a exposição dessas imagens pode expor tais pessoas à estigmatização.

Pensando nos CDs, vale lembrar que a divulgação de informações de pacientes pelos profissionais de saúde é tema que causa preocupações desde tempos mais remotos, antes da era comum, como exemplificado nos textos hipocráticos, ${ }^{14}$ que já ressaltavam a importância de o médico guardar segredo sobre as informações acessadas durante o exercício de sua função. É claro que esse tema ainda persiste ainda nos dias atuais, entretanto, o desenvolvimento tecnológico trouxe outras possibilidades de interação entre as pessoas, o que tem deixado os pacientes ainda mais vulnerabilizados nas relações com os profissionais da saúde quando o assunto é a imagem desses pacientes ${ }^{15}$.

Ainda assim neste trabalho observou-se que 61,7\% (76) das imagens foram publicadas por profissionais da saúde já formados. Para a discussão das imagens publicadas por profissionais, lembram-se os estudos de Loch, ${ }^{16}$ nos quais a autora apresenta como possibilidade de entendimento ao respeito à privacidade e à confidencialidade duas perspectivas: uma legal e outra ética. Aqui entender-se-á a perspectiva legal como aquela relacionada ao regramento por normas, incluindo assim, o código de ética da profissão e a perspectiva ética propriamente dita como aquela relacionada à filosofia da moral, aquela que busca fundamentar a ação moral.

Quando se trabalha na perspectiva legal, em geral, entende-se a privacidade como um direito pessoal, um direito à propriedade, expresso na Constituição Federal $^{17}$ do Brasil como um direito à intimidade: são invioláveis a intimidade, a vida privada, a honra e a imagem das pessoas, assegurado o direito à indenização pelo dano material ou moral decorrente de sua violação. O que é reafirmado no Código Civil ${ }^{18}$ por meio do direito à personalidade - a exposição ou a utilização da imagem de uma pessoa poderão ser proibidas, a seu requerimento e sem prejuízo da indenização que couber, se lhe atingirem a honra, a boa fama ou a respeitabilidade, ou se se destinarem a fins comerciais; e, finalmente pelo 
Código Penal, ${ }^{19}$ que trata sobre o crime de violação de segredo profissional, disposto no Art. 154, que estabelece: revelar alguém, sem justa causa, segredo, de que tem ciência em razão de função, ministério, ofício ou profissão, e cuja revelação possa produzir dano a outrem. Assim, em qualquer um dos casos apresentados neste trabalho, se um profissional da odontologia tenha utilizado a imagem do paciente sem o prévio consentimento livre e esclarecido do mesmo há risco desse profissional responder a um processo civil e criminal.

Entendendo o Código de Ética Odontológica como um documento normativo, tem o profissional inscrito tanto o direito quanto o dever de respeitar o sigilo de informações de pacientes, sendo tal desrespeito tratado como falta ética. Esta está evidenciada no Art. 14, inciso I: "revelar, sem justa causa, fato sigiloso de que tenha conhecimento em razão do exercício de sua profissão"20; e inciso III: "referência a casos clínicos identificáveis, exibir paciente, sua imagem ou qualquer outro elemento que o identifique, em qualquer meio de comunicação ou sob qualquer pretexto, salvo se o cirurgião-dentista estiver no exercício da docência ou em publicações científicas, nos quais, a autorização do paciente ou seu responsável legal, lhe permite a exibição da imagem ou prontuários com finalidade didático-acadêmicas" ${ }^{20}$.

Caberia, ainda, o entendimento por parte do setor de fiscalização dos CRO que a publicação feita nas redes sociais tem cunho comercial, ou seja, faz parte dos anúncios, propagandas e publicidades do profissional. Dessa forma, outra tipificação atribuída às publicações em que os profissionais exibem procedimentos, imagens do tipo antes e depois e de casos clínicos poderia ser relacionada ao Art. 44, inciso XII: "fazer publicidade e propaganda enganosa, abusiva, inclusive com expressões ou imagens de antes e depois, com preços, serviços gratuitos, modalidades de pagamento, ou outras formas que impliquem comercialização da Odontologia ou contrarie o disposto neste Código" ${ }^{20}$.

Considerando possível a interpretação de que o Instagram tem sido utilizado como um veículo de propaganda, mesmo porque foram identificados perfis de consultório/clínica $(9,7 \%)$, passa a ter maior destaque a publicação de imagens do tipo antes e depois. Isso porque o Código de Defesa do Consumidor $^{21}$ afirma que a propaganda veiculada integra o contrato que virá a ser celebrado entre o profissional e o paciente (art. 30). Ora, se o profissional veicula uma imagem de antes e depois, ele está se comprometendo com a obtenção de um resultado clínico específico, gerando expectativas em pacientes com diferentes características. Assim, passa a afirmar publicamente que os seus serviços prestados estão em uma ordem de obrigação de resultado e não de meio ${ }^{22}$.

Desse modo, nesta primeira perspectiva apresentada estaria contraindicado o uso de imagens de pacientes em redes sociais, em primeiro momento, por ser uma falta ética (em sentido normativo - deontológico), visto que se trata de um veículo leigo de comunicação e, em segundo momento, porque se não há autorização expressa do paciente para a obtenção da imagem e/ou para o seu uso em tais redes sociais, tratase de uma afronta aos direitos civis dos pacientes, estando o profissional suscetível a responder pelos seus atos em âmbito cível, penal e administrativo.

Já a perspectiva ética da necessidade do respeito à privacidade e à confidencialidade das informações pode ser discutida segundo teorias teleológicas e deontológicas ${ }^{16}$. Para os adeptos da perspectiva teleológica, ou consequencialista, não existem tipos de ações especiais que sejam corretas ou incorretas em si mesmas, a medida da retidão do ato só poderia ser avaliada quando se pensasse nas consequências dessa ação. Se as consequências forem as melhores possíveis naquele caso, tratou-se de uma ação boa. Para a deontologia, as consequências dos atos não justificam os meios que o agente moral utilizou para alcançá-los, assim, o que justificaria a não realização de determinada ação não é a sua possível consequência, mas sim, a percepção de que tal ação é má em si mesma ${ }^{23}$.

Assim, ao se explicar o dever ao respeito à privacidade e à confidencialidade sob uma perspectiva teleológica argumentar-se-á que os profissionais de saúde devem manter esse comportamento, pois, caso não façam, correm o risco de verem suas profissões caírem em descrédito, prejudicando a manutenção de relações sociais íntimas e o próprio exercício profissional $^{16}$.

Caso se utilize uma perspectiva deontológica, poderse-á argumentar que o segredo não deve ser quebrado, pois o profissional da saúde deve respeitar incondicionalmente a intimidade, a dignidade e a autonomia do paciente. Ora, se o paciente não sabe que sua imagem foi registrada e/ou em que condições e circunstâncias ela foi veiculada pode se afirmar que o profissional não respeitou o direito de o paciente decidir, e se este não autorizou, teve sua intimidade exposta e sua dignidade desrespeitada.

Se há a interpretação de que as imagens são utilizadas com fins de autopromoção, para atrair clientela, cabe ainda a avaliação sob a perspectiva kantiana, isto é, de que a ação é imoral, pois um agente moral deve tratar outro sempre como um fim em si mesmo e nunca apenas como um meio instrumentalizado para obtenção de algo de seu interesse ${ }^{24}$. No caso, os pacientes (procedimentos, casos clínicos, antes e depois) estão sendo utilizados como instrumentos para que a imagem do profissional seja ressaltada e ele consiga mais prestígio e clientela.

Entende-se que aos CRO cabe maior atenção a esse modismo tecnológico, sendo importante, em primeiro momento, a orientação quanto aos aspectos ético-normativos envolvidos e, em segundo momento, a fiscalização e aplicação da norma quando necessário. Também fica o desafio de intervenção nos contextos de formação em odontologia, assim, além das contribuições dos conselhos da profissão, destaca-se a importância das disciplinas de Bioética e Ética e Legislação, que têm momento privilegiado de discussão, afinal, são obrigatórias em todos os cursos de especialização (lato senso) 
em Odontologia, além de serem disciplinas comuns nos currículos dos cursos de graduação. Quando inseridas nos cursos de graduação, é interessante que a discussão aconteça em vários momentos do curso e que possa ser conduzida de modo interdisciplinar.

Entende-se que o aumento do número de pessoas que possuem smartphones e outros dispositivos que acessam a internet tem propiciado um contexto em que os pacientes estão cada vez mais vulneráveis a terem seus direitos desrespeitados. Há prejuízos diretos para os pacientes e para os profissionais e indiretos para a sociedade e para o prestígio da profissão.

Esses prejuízos podem ser cada vez mais frequentes, principalmente porque grande parte das pessoas que utiliza essas ferramentas não compreende a natureza das informações que compartilham por uma espécie de ingenuidade geracional, uma vez que não fazem parte da geração dos "nativos digitais" 25 . Pessoas que recentemente passaram a utilizar as redes sociais estão mais vulneráveis a compartilhar, por exemplo, o local de onde publicam suas informações, simplesmente porque desconhecem que essa informação é automaticamente publicada por um mecanismo de georreferenciamento, caso o usuário não o desabilite.

Outro problema específico da era digital se relaciona com os mecanismos de memória eterna. Ao postar alguma informação em rede social, os servidores ou até mesmo outros usuários dessa rede podem salvar as informações inseridas. Daí em diante a informação poderá ser reproduzida em larga escala e também sempre poderá reaparecer, mesmo que o usuário da postagem original tenha se arrependido e deletado essas informações ${ }^{25}$.

\section{Conclusão}

As imagens encontradas na rede social Instagram demonstram que alguns cirurgiões-dentistas têm desrespeitado os princípios do CEO por publicarem imagens de pacientes em veículo de comunicação leiga, além de potencialmente estarem desrespeitando a privacidade dos pacientes e o dever de confidencialidade que devem a estes.

Evidencia-se que esses profissionais deixam de se acautelar ética e legalmente em suas práticas profissionais, perdendo a oportunidade de aplicarem um gerenciamento de risco mais efetivo, tornando-se alvos fáceis para se transformarem em réus em processos em âmbitos cível, criminal e éticoadministrativo.

Agrava a situação o fato de que as postagens em redes sociais podem ser copiadas por outros usuários, ampliando a dimensão da exposição dos pacientes, que pode se alastrar em níveis mundiais. Além disso, caso o próprio profissional se arrependa de sua ação e apague as informações postadas, caso alguém tenha feito cópias dessas informações, o profissional terá dificultado o seu direito ao esquecimento, uma vez que essas informações poderão reaparecer novamente, ainda que se tenha passado muitos anos e o comportamento moral do profissional tenha se transformado radicalmente. Diante desse contexto, recomenda-se cautela e prudência aos profissionais que se aventuram a divulgar informações de seus pacientes em redes sociais.

\section{Referências}

1. Silva M. Documentação em odontologia e sua importância jurídica. Odontol Socied 1999;1(1/2):1-3.

2. Serra MC, Fernandes CMS. Obtenção e utilização de imagens de pacientes: proposta de termo de consentimento à luz do direito brasileiro. Rev Âmbito Juríd 2011;14(93).

3. Fortes PAC. Reflexões sobre a bioética e o consentimento esclarecido. Bioética 1994;2(2):129-35.

4. Arata Jr. S. Novos desafios à privacidade: os círculos sociais e as redes sociais (sociais networks). Saúde Ética Justiça 2003;8(1/2):44-56.

5. Clark JR. Do you still "like" Facebook? Air Med J 2013;32(4):184-7.

6. Dias OV, Gomes LMX, Barbosa TLA, Souza LPS, Rocha ALF, Costa SM. Segredo profissional e sua importância na prática de enfermeiros e odontólogos Rev. Bioét 2013;21(3):448-54.

7. Rosa FM, Ferndandes MM, Daruge Junior E, Paranhos LR. Danos materiais e morais em processos envolvendo cirurgiõesdentistas no estado de São Paulo. RFO 2012;17(1):26-30.

8. Cruz RM, Cruz CPAC. Gerenciamento de riscos na prática ortodôntica-como se proteger de eventuais problemas legais. Rev. Dental Press Ortodon Ortop Facial 2008;13(1):141-56.

9. Campos CJG. Método de análise de conteúdo: ferramenta para a análise de dados qualitativos no campo da saúde. Rev Bras Enferm 2004;57(5):611-4.

10. Brasil. Conselho Federal de Odontologia. Resolução n ${ }^{\circ} 63$, de 8 de abril de 2005, atualizado em 17 de março de 2010. Cria e aprova a Consolidação das Normas para Procedimentos nos Conselhos de Odontologia e normatiza as atividades do funcionamento interno dos Conselhos. Diário Oficial da União. 19 abr. 2005; Seção I, p. 104.

11. Creswell, JW. Projeto de pesquisa: métodos qualitativo, quantitativo e misto. Porto Alegre: Artmed; 2010.

12. Freitas SFT, Kovaleski DF, Boing AF. Desenvolvimento moral em formandos de um curso de odontologia: uma avaliação construtivista. Ciênc Saúde Coletiva 2005;10(2):453-62.

13. Dias ACG, Teixeira MAP. Self-disclosure in the Internet: a study with university students. Aletheia 2008;(27):23-35.

14. Rule JT, Veatch RM. Ethical questions in dentistry. Illinois: Quintessence; 1993.

15. Martorell LB, Nascimento WF, Garrafa V. Redes sociais, privacidade, confidencialidade e ética: a exposição de imagens de pacientes no facebook. Interface 2016; 20(56):13-23.

16. Loch JA. Confidencialidade: natureza, características e limitações no contexto da relação clínica. Bioética 2003;11(1):51-64.

17. Brasil. Constituição da República Federativa do Brasil. Diário Oficial da União. 5 out. 1988. [acesso 21 nov 2014]. Disponível em http://www.planalto.gov.br/ccivil_03/ constituicao/constituicao.htm

18. Brasil. Lei ${ }^{\circ} 10.406$, de 10 de janeiro de 2002. Código civil. Diário Oficial da União. 11 jan. 2012 [acesso em 21 nov. 2014]. Disponível em http://www.planalto.gov.br/ccivil_03/ leis/2002/110406.htm

19. Brasil. Lei n ${ }^{\circ} 2.848$, de 7 de dezembro de 1940. Código penal. Diário Oficial da União. 31 dez. 1940 [acesso 21 nov 2014]. 
Disponível em http://www.planalto.gov.br/ccivil 03/decretolei/Del2848compilado.htm

20. Brasil. Conselho Federal de Odontologia. Resolução n ${ }^{\circ} 18$, de 11 de maio de 2012. Revoga o Código de Ética Odontológica aprovado pela Resolução CFO-42/2003 e aprova outro em substituição. Diário Oficial da União. 14 jun. 2012;(114): Seção I, p. 118.

21. Brasil. Lei $\mathrm{n}^{\circ} 8.078$, de 11 de setembro de 1990. Código de defesa do consumidor. Diário Oficial da União. 11 dez. 1990 [acesso 22 nov 2014]. Disponível em http://www.planalto. gov.br/ccivil_03/leis/18078.htm
22. Pittelli SD, Mota MV. A prestação obrigacional do dentista como obrigação de resultado. Saúde Ética Justiça 2012;(17)1:26-9.

23. Davis NA. La Deontología contemporánea. In: Singer P. Compendio de ética. Madri: Alianza; 2004. p.291-308.

24. Kant I. Fundamentação da metafísica dos costumes. Lisboa: Edições 70; 2007.

25. Pazzinatto $\mathrm{CH}$, Freitas $\mathrm{COA}$. O direito ao esquecimento frente aos mecanismos de memória eterna. Rev Opin Jur 2015;13(17):82-107. 